NBER WORKING PAPER SERIES

\title{
EXPORT-PLATFORM FOREIGN DIRECT INVESTMENT
}

\author{
Karolina Ekholm \\ Rikard Forslid \\ James R. Markusen \\ Working Paper 9517 \\ http://www.nber.org/papers/w9517
NATIONAL BUREAU OF ECONOMIC RESEARCH
1050 Massachusetts Avenue
Cambridge, MA 02138
February 2003

The views expressed herein are those of the author and not necessarily those of the National Bureau of Economic Research.

(C2003 by Karolina Ekholm, Rikard Forslid, and James R. Markusen. All rights reserved. Short sections of text not to exceed two paragraphs, may be quoted without explicit permission provided that full credit including Cnotice, is given to the source. 
Export-Platform Foreign Direct Investment

Karolina Ekholm, Rikard Forslid, and James R. Markusen

NBER Working Paper No. 9517

February 2003

JEL No. F13, F23

\section{ABSTRACT}

Export-platform foreign direct investment in which the affiliate's output is (largely) sold in third markets rather than in the parent or host markets has received empirical attention recently, but little theoretical analysis. This paper is an attempt to make some sense of this phenomenon. We use a three-region model in which there are two identical, large, high-cost economies and a small lowcost economy. Pure export-platform production arises in a symmetric case, when a firm in each of the high-cost economies has a plant at home, and a plant in the low-cost country (the South) to serve the other high-cost country. This occurs when trade costs for intermediates (components) and plantfixed costs are moderate and the South has a moderate cost advantage in assembly. Another interesting and empirically important case arises when there is trade liberalization between one of the high-cost countries and the small, low-cost country. The outside high-cost country may wish to build a branch plant inside the free trade area due to market size, but chooses the low-cost country on the basis of cost. Or a firm headquartered in the large country inside the free-trade area might build a single plant in its low-wage partner in order to serve their joint free-trade area and to export to the outside high-cost country.

Karolina Ekholm

Department of Economics

Stockholm School of Economics

SE-113 83 Stockholm

Sweden

Karolina.Ekholm@hhs.ne

James. Markusen

Department of Economics

University of Colorado

Boulder CO 80309-0256

USA

and NBER

james.markusen@colorado.edu
Rikard Forslid

Department of Economics

University of Stockholm

SE-106 91 Stockholm

Sweden

rf@ne.su.se 


\section{1. $\quad$ Introduction}

Export-platform FDI is generally defined as investment and production in a host country where the output is largely sold in third markets, not the parent or host-country markets. It is not clear how to view these investments in the terminology of current FDI theory, where the principal distinction is between horizontal or market-seeking production and vertical or resource-seeking investments. Platform FDI has elements of both. Often, production is to serve a large integrating market with a branch plant as in horizontal investments but a specific location within the region is chosen on the basis of cost considerations, as in vertical investments. US investments in Ireland, for example, have these characteristics: branch plants are used to serve the integrated EU, but Ireland is chosen as the low-cost location. A second example would be a European firm producing in Mexico to serve the integrated North American market.

The importance of export platform FDI is documented in a study by Hanson, Mataloni, and Slaughter (2001). Using data on the foreign operations of U.S. multinationals, they report that although the average share of exports in affiliate sales has remained constant at about one third, there has been a substantial increase in Mexico and Canada after the formation of NAFTA. Their econometric analysis suggests that export platform FDI is promoted by low host-country trade barriers and discouraged by large host-country markets. The former observation is consistent with the predictions of our analysis, while the latter may serve as a justification for the strong assumption about zero demand in the South we introduce below. ${ }^{1}$

\footnotetext{
${ }^{1}$ Note that according to this definition of export platform FDI, situations where the foreign affiliate exports back to the home country are included, i.e. situations that we define as purely vertical FDI in this paper.
} 
Table 1 presents some summary statistics that motivate the analysis. The data are sales by foreign affiliates of US multinationals, broken down into local sales in the host market, export sales back to the US, and export sales to third markets (data complied and analyzed in Markusen and Maskus 2001, 2002). The first line of data presents figures for all 34 host countries in the data set, and subsequent lines present three groups of countries where there is some common feature of the group data.

The first group of countries, Ireland, Belgium and Holland has the highest proportion of affiliate sales going to third countries of all countries in the sample, and very low proportions of their sales going back to the US. The countries which display export-platform sales most clearly are not developing countries, but smaller countries inside the EU. These countries clearly fit the conceptual idea expressed above, that the export-platform phenomenon may be most important when an outside firm chooses a low-cost location inside a free-trade area to serve the entire freetrade area. If we want to think of the EU as a single market, then these investments would be thought of as horizontal production in the traditional sense: US firms producing in Europe to serve the European market. But when we disaggregate the EU, we then see the export-platform phenomenon in the data.

The second group of countries, Singapore, Malaysia, and Hong Kong display a concentration of their sales in exports relative to local sales, but there is a balance between exports back to the US and exports to third countries. Comparing these numbers to the average for all countries in the first row of data, we see in fact that sales for these countries is concentrated in exports back to the US relative to the average. Thus production in these countries fits more closely with the traditional notion of vertical investments. 
The third group of countries in Table 1 are the US's NAFTA partners, Canada and Mexico, although NAFTA was just coming into effect at the time of these data (the US-Canada free trade agreement took effect in January 1989). ${ }^{2}$ Local sales in these countries are close to the proportions for the total sample, in part reflecting the fact that both countries are big markets and likely reflecting the fact that these numbers for Mexico reflect import-substituting horizontal production prior to NAFTA. The interesting thing about these data are that the shares of export going to the US and to third countries are more or less the reverse of those for the first group of countries. In these cases, the US multinational is inside the free-trade area, and so foreign affiliate exports are concentrated in sales back to the US rather than to third countries.

The purpose of this paper is to present a simple model showing the conditions under which export-platform FDI is likely to arise and the conditions under which sales to third countries dominates the affiliate's production. We present a three-region model in which two regions are identical, large markets. ${ }^{3}$ These regions and their firms are denoted $\mathrm{W}$ (west) and $\mathrm{E}$ (east) and collectively these two regions are referred to as $\mathrm{N}$ (north). We are thinking here of the US-Canada market and the EU. The third country is a small, low-wage country, denoted S

\footnotetext{
${ }^{2}$ The Markusen-Maskus data set has been extended to 1997, but we do not yet have the breakdown of total affiliate exports into exports to the US and exports to third countries. In the 1997 data, Mexican affiliates exported $52 \%$ of their output, versus $34 \%$ in Table 1 . We suspect, but cannot be sure at this point, that the exports are highly concentrated in sale back to the US.

${ }^{3}$ To the best of our knowledge, the only other theoretical treatment of export-platform investment is Motta and Norman (1996). They analyze the effect of regional integration in a three-region model where there is one firm in each country and there are identical demand and cost conditions in all countries. In their model, final goods production takes place in one single stage so there is no scope for vertical FDI. . If the outside firm chooses to set up a plant inside the bloc, there will be an element of export platform FDI because part of the output of that plant will be exported to the other country inside the bloc. Our model also relates in a few ways to more general analyses of production fragmentation: see analyses in Jones (2000) and Arndt and Kierzkowski (2000).
} 
(south). Firms $\mathrm{W}$ and E produce an intermediate good, components, in their home market, but may assemble components in the other northern market or in the south.

Since there are a great many possible configurations of plants and trade routes in such a model, we will make a number of restrictive assumptions to reduce the possibilities to a manageable number. We assume that the world has two firms in the multinationalized sector, one headquartered in each of the large, high-wage markets. We also assume that there is no domestic demand in the small, low-wage country, so that all output of affiliate plants (if any) in that country is exported. These two assumptions alone greatly reduce the number of cases that must be considered.

The first case we consider involves symmetric trade costs on all links, so that the two firms will each adopt the same number of plants, and either both or neither will have a plant in $S$ and, when they do, the export patterns of those plants will be symmetric. Beginning with a high cost for trading components and a small assembly cost advantage for $\mathrm{S}$, we show that gradually lowering these two costs results in an interesting sequence of equilibria. First, $\mathrm{W}$ and $\mathrm{E}$ maintain a single plant in their home country and serve the other northern market by exports, a purely national-firm strategy. Then each northern firm builds a branch plant in the other northern country, serving the foreign market with local production, a purely horizontal strategy. Third, each firm maintains a home plant for its home market, and a plant in S which solely serves the other northern market, a purely export-platform strategy. Finally, at a sufficiently low cost for trading components and a sufficiently large cost advantage for $\mathrm{S}$, each firm chooses a single assembly plant in S which serves the firm's own market and the other northern market, a vertical strategy with respect to a firm's own market but an export-platform strategy with respect to the 
firm's northen rival. We shown the volume of affiliate production and the volume of trade under these different regimes and discuss issues such as whether or not affiliate production and trade are complements or substitutes.

The second case we present is motivated by the discussion of free-trade areas above and by the data in Table 1 . We assume that $\mathrm{W}$ and $\mathrm{S}$ form a free trade area. Firm E must pay a trade cost to ship components to a plant in $\mathrm{S}$ (if there is one) and a cost to ship final output back to $\mathrm{E}$, but enjoys costless shipping of final output to $\mathrm{W}$ from its plant in $\mathrm{S}$. The cost to firm $\mathrm{E}$ of shipping components to a plant in $\mathrm{S}$ puts that firm at a strategic disadvantage relative to firm $\mathrm{W}$. Gradually lowering certain costs, such as the production cost in S, results in a series of regime shifts. Firm $\mathrm{W}$ is the first to invest in $\mathrm{S}$, using the latter plant to serve its own market and $\mathrm{E}$. Then firm E builds a plant in S to serve $\mathrm{W}$, but retains its plant in its home market, so that its plant in $\mathrm{S}$ is a pure export-platform investment. This is reminiscent of the data in Table 1 for Ireland, for example. Then at quite low costs in S, firm E closes its home plant and produces in $\mathrm{S}$ for both markets.

Among other things, this case illustrates the strategic advantage to a firm of having a freetrade agreement with a low-wage partner in order to gain not only a direct cost advantage, but also an indirect profit-shifting advantage over its rival reminiscent of many results from the strategic trade-policy literature. In the first case (symmetric trade costs), the shift to exportplatform production in S may lower the profits of both firms, but this is a prisoner's dilemma problem. More generally, if your rival is going to shift to a low-cost location or gain a low-wage partner (case 2), you better do so as well. 


\section{2. $\quad$ A Three-Region Model}

Elements of the model are as follows:

There are three countries: E (east), W (west), and S (south).

$\mathrm{E}$ and $\mathrm{W}$ are identical; together they can be referred to as the north $(\mathrm{N})$

$\mathrm{S}$ is small, low-cost country

Two final-goods sectors and one intermediate good (three goods in total)

Y constant returns, perfect competition

$\mathrm{X}$ increasing returns and imperfect competition

$\mathrm{Z}$ intermediate good used in $\mathrm{X}$, sometimes referred to as "components"

One factor of production, $\mathrm{L}$ (labor), constant marginal costs in $\mathrm{Z}$ and $\mathrm{X}$ activities

One unit of $\mathrm{Z}$ is needed to produce one unit of $\mathrm{X}$.

There is a fixed cost $\mathrm{F}$ for a first plant, and a fixed cost $\mathrm{G}$ for any subsequent plants.

There are trade costs for $\mathrm{X}$ and $\mathrm{Z}$ that are specific to each link, some of these may be zero.

Assume that there are two firms producing $\mathrm{X}$, one headquartered in $\mathrm{W}$ and one in $\mathrm{E}$, and these can be referred to as firms W and E respectively. Assume that each firm must produce its intermediate good $\mathrm{Z}$ in its home country. Production of $\mathrm{X}$ or "assembly" as we shall sometimes refer to it may be done in any or all countries. A firm can ship components to a foreign assembly plant and that plant may in turn serve only the local market or export to one or both of the other countries. If a firm wants only one plant in the north, it will choose its home country (e.g., firm W will not have a single plant in E).

This simple model still leave a great many possible outcomes to consider, and so we will make one additional assumption that greatly simplifies the set of outcomes, but still leaves a rich set of possibilities to consider. We assume that $\mathrm{S}$ has no domestic demand, and so neither firm will build a plant in $\mathrm{S}$ simply to serve $\mathrm{S}$. 
The term regime will denote the number and location of plants. Regimes will be denoted by a two or three-letter code, with the first letter referring to the firm, and the second and third (if any) letters referring to its plant locations. WW, for example, means that firm $\mathrm{W}$ has an assembly plant in W and WWS means that firm W has assembly plants in W and S. In the latter case, it must be true that the plant in S only serves E, since S has no demand, and the firm would not have a plant in $\mathrm{S}$ to serve its home market (W) when it has a plant there as well and would not serve E from both $\mathrm{W}$ and $\mathrm{S}$ given the existence of constant marginal costs and plant-specific fixed costs.

Let superscript $\mathrm{W}$ or $\mathrm{E}$ refer to the identity of the firm. A double subscript is used on $\mathrm{X}$ quantities along with the firm-identifier superscript. The first subscript is the country of production and the second is the country of sale. $X_{i j}^{k}$ is then production by firm k in country $\mathrm{i}$ which is sold in country $\mathrm{j}$. Sales of $\mathrm{X}$ in each region can come from five possible sources (firms and countries). Sales in W can come from local production of its own firm, imports from E's production in E, imports of its own firm's production in $S$, and imports of E's production in $S$ and from E's production in a plant in $\mathrm{W}$. Let $\mathrm{p}$ denote the price of $\mathrm{X}$ in a region in terms of $\mathrm{Y}$. Inverse demand functions are given by:

$$
\begin{aligned}
& p_{w}=\alpha-\beta\left(X_{w w}^{w}+X_{e w}^{e}+X_{s w}^{w}+X_{s w}^{e}+X_{w w}^{e}\right) \\
& p_{e}=\alpha-\beta\left(X_{w e}^{w}+X_{e e}^{e}+X_{s e}^{w}+X_{s e}^{e}+X_{e e}^{w}\right)
\end{aligned}
$$

All intermediate production of Z occurs in a firm's home region by assumption, and the unit cost will be denoted $c_{z}$, identical in $\mathrm{W}$ and $\mathrm{E}$. A subscript ' $\mathrm{n}$ ' denotes the common value for 
$\mathrm{W}$ and E. $\mathrm{c}_{\mathrm{xn}}$ denotes the cost of assembly in the north and $\mathrm{c}_{\mathrm{xs}}$ the cost in the south. Notation for the unit cost of $\mathrm{X}$ assembled in each of the three regions is then:

$$
c_{n}=c_{x n}+c_{z} \quad c_{s}=c_{x s}+c_{z}
$$

The per-unit specific trade costs for the final (assembled) good will be denoted $\tau$, and the specific trade cost for a unit of $\mathrm{Z}$ will be denoted $\sigma$. We will restrict ourselves again to symmetry between $\mathrm{W}$ and $\mathrm{E}$, so the common values of these trade costs will be denoted $\tau_{\mathrm{n}}$ and $\sigma_{\mathrm{n}}$. The W-S and E-S links do not have to bear the same costs, so we will need double subsricpts on these lengths. On a given link, we assume, however, that the cost is the same in both directions, so the ordering of the subscripts does not matter. Components only flow from north to south. These costs are then given by

$$
\tau_{w s}=\tau_{s w}, \quad \tau_{e s}=\tau_{s e}, \quad \sigma_{w s}, \quad \sigma_{e s}
$$




\section{3. $\quad$ A Symmetric Case}

In this section, we will consider only symmetric trade costs for the two firms. We argue in the appendix that only symmetric outcomes are candidates for equilibria, and no asymmetric outcomes were found in our simulations (we eliminate cases where fixed costs are so high that only one firm can exist in equilibrium). Candidate regimes in the symmetric case are as follows: WW EE pure national firm regime: each firm serves its rival's market by exports

WWE, EEW pure horizontal firm regime: each firm serves its rival's market with a local plant

WWS, EES

pure export-platform regime: each firm serves its rival's market from a plant in $\mathrm{S}$

WS ES vertical/export-platform regime: each firm serves its rival's market and its own market from a single plant in $\mathrm{S}$

Equilibrium is found as the sub-game perfect solution to a two-stage game in which firms first select the number and location of their plants, and then play a Cournot-Nash game in outputs. Consider the second stage first and assume that the regime is the national firm outcome, WW EE. This duopoly problem is reasonably well known so to algebra is relegated to an appendix. Equilibrium quantities are:

$$
X_{w w}^{w}=X_{e e}^{e}=\frac{\alpha-c_{n}+\tau_{n}}{3 \beta}
$$

$$
X_{w e}^{w}=X_{e w}^{e}=\frac{\alpha-c_{n}-2 \tau_{n}}{3 \beta}
$$

As we will note later, this regime can occur when $\mathrm{G}$ and the cost of trading components 
are relatively high and S's cost advantage is relatively small. Consider next the the horizontal outcome WWE EEW. Equilibrium quantities are:

$$
X_{w w}^{w}=X_{e e}^{e}=\frac{\alpha-c_{n}+\sigma_{n}}{3 \beta}
$$

$$
X_{e e}^{w}=X_{w w}^{e}=\frac{\alpha-c_{n}-2 \sigma_{n}}{3 \beta}
$$

As we will note later, this regime can occur when the cost of trading components is small (relative to $\tau$ ), $\mathrm{G}$ is small and S's cost advantage is relatively small. Now consider the pure export-platform case in which each firm maintains a plant in its home country to serve its own market and a plant in S to serve its rival: WWS EES. Equilibrium quantities are now:

$$
\begin{aligned}
& X_{w w}^{w}=\frac{\alpha-\left(2 c_{n}-c_{s}\right)+\sigma_{e s}+\tau_{s w}}{3 \beta} \quad X_{s e}^{w}=\frac{\alpha-\left(2 c_{s}-c_{n}\right)-2 \sigma_{w s}-2 \tau_{s e}}{3 \beta} \\
& X_{e e}^{e}=\frac{\alpha-\left(2 c_{n}-c_{s}\right)+\sigma_{w s}+\tau_{s e}}{3 \beta} \quad X_{s w}^{e}=\frac{\alpha-\left(2 c_{s}-c_{n}\right)-2 \sigma_{e s}-2 \tau_{s w}}{3 \beta}
\end{aligned}
$$

Suppose finally that each firm produces only from a plant in S (regime WS, ES), incurring trade costs on components and costs to shift X back home. Outputs are now:

$$
X_{s w}^{w}=\frac{\alpha-c_{s}-\sigma_{w s}-\tau_{s w}}{3 \beta} \quad X_{s e}^{w}=\frac{\alpha-c_{s}-\sigma_{w s}-\tau_{s e}}{3 \beta}
$$




$$
X_{s e}^{e}=\frac{\alpha-c_{s}-\sigma_{e s}-\tau_{s e}}{3 \beta} \quad X_{s w}^{e}=\frac{\alpha-c_{s}-\sigma_{e s}-\tau_{s w}}{3 \beta}
$$

Let $\pi_{\mathrm{ij}}^{\mathrm{w}}$ denote the profits for firm $\mathrm{W}$ when it has plants in $\mathrm{i}$ and $\mathrm{j}$. It is also reasonably well known that in this familiar model, profits are just the sum of $\beta$ times the squared outputs sold in each market minus fixed costs. These formulae are also derived in the appendix. Profits in the four regimes are given by the following formulae, with identical expressions for firm E.

$$
\begin{array}{ll}
\pi_{w}^{w}=\beta\left(X_{w w}^{w}\right)^{2}+\beta\left(X_{w e}^{w}\right)^{2}-F & (\text { WW EE) } \\
\pi_{w e}^{w}=\beta\left(X_{w w}^{w}\right)^{2}+\beta\left(X_{e e}^{w}\right)^{2}-F-G & (\text { WWE EEW) } \\
\pi_{w s}^{w}=\beta\left(X_{w w}^{w}\right)^{2}+\beta\left(X_{s e}^{w}\right)^{2}-F-G & (\text { WWS EES) } \\
\pi_{s}^{w}=\beta\left(X_{s w}^{w}\right)^{2}+\beta\left(X_{s e}^{w}\right)^{2}-F & (\text { WS ES) }
\end{array}
$$

Solving for the equilibrium regime analytically is complicated by the fact that the output levels differ by regime and that profits are quadratic in outputs. Let us first consider a simple experiment in which the firm wants to supply a fixed and equal amount of output to each market in order to gain some intuition. Then we can simply add the (unit) cost of supplying each market together to get total costs, with the caution that the low-cost option is not necessarily the Nash equilibrium regime (the usual prisoner's dilemma phenomenon). Let $\mathrm{g}$ be the unit plant fixed costs for this fixed quantity ( $\mathrm{G}$ divided by this reference quantity). Here are the conditions for firm $\mathrm{W}$ to prefer the pure export-platform option on a cost basis, with those for firm $\mathrm{E}$ being identical (assume $\sigma$ on all links is the same and similarly for $\tau$ ). 
Plants in W and S preferred to a single plant in S only (WWS EES cheaper than WS ES)

$$
\begin{gathered}
\left(c_{n}+g\right)+\left(c_{s}+\sigma+\tau+g\right)<\left(c_{s}+\sigma+\tau+g\right)+\left(c_{s}+\sigma+\tau\right) \\
\Rightarrow c_{n}+g<c_{s}+\sigma+\tau
\end{gathered}
$$

Plants in W and S preferred to plants in W and E (WWS EES cheaper than WWE EEW)

$$
\begin{gathered}
\left(c_{n}+g\right)+\left(c_{s}+\sigma+\tau+g\right)<\left(c_{n}+g\right)+\left(c_{n}+\sigma+g\right) \\
\Rightarrow c_{n}>c_{s}+\tau
\end{gathered}
$$

Plants in W and S preferred to plants in W only (WWS EES cheaper than WW EE)

$$
\begin{gathered}
\left(c_{n}+g\right)+\left(c_{s}+\sigma+\tau+g\right)<\left(c_{n}+g\right)+\left(c_{n}+\tau\right) \\
\Rightarrow c_{n}>c_{s}+\sigma+g
\end{gathered}
$$

Let $\Delta \mathrm{c}=\mathrm{c}_{\mathrm{n}}-\mathrm{c}_{\mathrm{s}}>0$, the cost disadvantage of the north. Then our three conditions for the firms to prefer pure export-platform FDI on a cost basis are

$$
\Delta c<\sigma+\tau-g \quad \text { (WWS EES cheaper than WS ES) }
$$

$$
\Delta c>\tau \quad \text { (WWS EES cheaper than WWE EEW) }
$$

$\Delta c>\sigma+g$

(WWS EES cheaper than WW EE)

The first inequality says that, for the firm to prefer pure export-platform production on a cost basis to a single plant in $\mathrm{S}$, the cost disadvantage of producing at home for the home market is less than the cost of shipping components to $\mathrm{S}$ and shipping $\mathrm{X}$ back home, minus the added cost of having two plants. The second inequality says that, for the firm to prefer pure exportplatform production to horizontal production to it must be that the cost disadvantage of producing in the (other) northern market is greater than the cost of shipping $\mathrm{X}$ from $\mathrm{S}$. The third inequality says that, for the firm to prefer pure export-platform production to a single home plant serving the other country by exports, the cost disadvantage must exceed the cost of shipping 
components to $\mathrm{S}$ plus the fixed costs of a second plant.

Consider a knife-edged case where all three equalities hold as equations. This will be true when

$$
\Delta c=\tau=2 \sigma=2 g
$$

There are various ways to adjust the parameters so that all three inequalities in (19) hold. Hold trade costs on $X, \tau$, constant. Then all three inequalities can be satisfied if we raise the north's cost disadvantage, but lower plant fixed-costs by a greater amount. Or for a given northern cost disadvantage, we could lower $\tau$ but lower g by even more. It is interesting and perhaps counter intuitive to note that the pure export-platform case requires $\sigma$ to be positive. If it is zero, each firm would prefer to have a single plant in S only if the second and third inequalities hold.

To summarize, we could (with some vagueness) say that the pure export-platform case is preferred on a cost basis if the cost disadvantage of the north is (a) large relative to the cost of shipping final output (so that a horizontal strategy is not preferred) and (b) large relative to the cost of shipping components and the per-unit fixed costs of a second plant (so that a nationalfirm strategy is not preferred), but (c) not large relative to the cost of shipping components to S, and shipping final output back to the home and incurring the added per-unit fixed costs of the second plant (so that a single plant in $\mathrm{S}$ is not preferred).

The fact that a certain regime is the cheapest does not, of course imply that it is the Nash equilibrium. In addition, we have made the simplifying assumption here that outputs are fixed and constant across markets and regimes. We have devoted a considerable amount of time to solving for the Nash equilibrium analytically. The conditions are sometimes messy, due in large 
part to the differing outputs and the fact that profits are quadratic functions of these differing outputs.

What we have found is that much of the basic intuition in (20) comes through in the more complex conditions, which check proposed equilibria for profitable deviations. For example, we tend to find that the pure export-platform case (WWS EES) falls between the horizontal case (WWE EEW) and the mixed vertical export-platform case (WS ES). From (20), the exportplatform case is the cheapest of the three when

$$
\tau<\Delta c<\sigma+\tau-g
$$

where $\mathrm{g}$ is defined as plant fixed costs per unit of output. In the appendix to the paper, we illustrate that, beginning with the export-plant form regime WWS EES, firm W will not want to deviate to WWE EES (horizontal production) when

$$
\Delta c>\tau \quad \text { (deviation from WWS EES to WWE EES unprofitable) }
$$

which is the same as the left-hand inequality in (22). This case is relatively easy, since there is no change in plant fixed costs in the proposed deviation, and both firm's supplies to market W don't change, thus allowing us to get around the quadratic problem.

The condition that firm $\mathrm{W}$ does not want to deviate from a export-platform production to a single plant in $\mathrm{S}$ when $\mathrm{E}$ chooses EES is more messy, but again the appendix shows that the condition is similar to the right-hand inequality in (22). We establish that a sufficient condition for a deviation by W from WWS EES to WS EES to be unprofitable is:

$$
\Delta c>\sigma+\tau-\frac{3}{4}\left[\frac{G}{X_{h}^{w}}\right] \quad \text { (deviation from WWS EES to WS EES unprofitable) }
$$


where $X_{h}^{w}$ is the average output per plant of a firm in the horizontal equilibrium. Thus (24) involves a fixed cost per unit of output on the right-hand side similar to (22).

Finally, the appendix also shown that a sufficient condition for a deviation by firm $\mathrm{W}$ from WWS EES to WW EES (deviating to a national firm strategy) to be unprofitable is:

$$
\Delta c>\sigma+\frac{3}{4}\left[\frac{G}{X_{w e}^{w}}\right] \quad \text { (deviation from WWS EES to WW EES unprofitable) }
$$

where $X_{n}^{w}$ is the quantity that a firm exports to the other northern country in the national firm duopoly from (6). Thus (25) is similar to the third inequality in (20) using the appropriate definition of fixed costs per unit.

We have reason to suspect, therefore, that the intuition presented following (20) is a good guide to the true analytical solution. Therefore, we will now turn to simulations.

Figure 1 presents numerical simulations for the model over a grid of values of $\sigma$ and $c_{s}$, with the values of $\tau=1 c_{n}=4$ and $G=1.1$ held constant. ${ }^{4}$ The profits for the two firms are calculated to form a $4 \times 4$ payoff matrix, in which each firm has four strategies: a single plant at home, plants at home and in the other northern country, a plant at home and in S, and a plant in S only. The simulation program then finds all pure-strategy Nash equilibria over this $4 \times 4$ payoff matrix. No cases of asymmetric Nash equilibria were found for this simulation.

The top panel of Figure 1 gives the equilibrium regime for a $21 \times 21$ grid of values, and the

${ }^{4}$ Other parameter values held constant in this section and in the next section are $\alpha=12, \beta$ $=1$, and $\mathrm{F}=3$ 
bottom panel displays the (identical) profits of the two firms. Highest values for $\sigma$ and $\mathrm{c}_{\mathrm{s}}$ are found in northwest corner of the top panel and the west corner of the bottom panel (this was chosen because this is the best viewing rotation in the bottom panel, and then we tried to make the top panel consistent with that). Both costs decrease along the diagonal line moving to the southeast (top panel) or east (bottom panel).

When the cost of trading components is high and the south has a small cost advantage, the equilibrium regime is WW EE: each firm has a single plant at home and serves the other northern country by exports. As the cost of trading components falls, each firm opens a second plant, in S if production costs in S are low, or in the other northern country if the south's advantage is small. When both component trade costs are low and the south has a big advantage, both firm just maintain a single plant in S: WS ES. The bottom panel of Figure 1 shows that both firms' profits suffer in the two-plant strategies. This is the usual prisoner's dilemma outcome: at these parameter values each firm has an incentive to switch to two plants if its rival has a single plant, but when both firms do this profits fall.

Figure 2 looks at the diagonals shown in Figure 1 with high values of $\sigma$ and $c_{s}$ at the left and low values on the right. The drop in profits when the firms invade each others market with a branch plant is a pro-competitive effect which harms the firms and they incur the added plant fixed cost G. In the initial WW EE national-firm strategy, the trade costs on X "insulate" the firms somewhat from competing with one another, an effect familiar from the strategic tradepolicy literature. Profits rebound when the firms switch to a single plant in S, an effect largely due to the saving of $\mathrm{G}$ on the second plant. Consistent with our earlier discussion, the pure export-platform outcome WWS EES occurs at moderately low values of $\sigma$ and $\mathrm{c}_{\mathrm{s}}$, but not so low 
that the firms close their domestic plants.

Figures 3-5 present other statistics for the same diagonal as in Figure 2. Figure 3 shows the volume of affiliate production, defined as quantities of $\mathrm{X}$ assembled in plants other than in the firms' home countries. In the initial national-firm regime this is zero, and rise to approximately half of world X production in the two middle two-plant regimes. Affiliate production is $100 \%$ of world production in the WS ES regime by definition.

Figure 4 shows the volume of $\mathrm{X}$ trade. In the first regime switch to horizontal production (WWE EEW), trade in $\mathrm{X}$ falls to zero while affiliate production in Figure 3 jumps to about half of world output. Multinational production substitutes here for trade in X and all foreign production is sold in the host-country market. When plants are opened in the south, both affiliate production and trade in $\mathrm{X}$ are high, since all of the outputs from plants in $\mathrm{S}$ is exported. Multinational production then complements trade in X. This same pattern is true in the bottom pattern when trade in $\mathrm{X}$ and $\mathrm{Z}$ are added together $\mathrm{Z}$ is assumed to have a value share of 0.5 in $\mathrm{X}$ ), except that this trade volume does not fall to zero in the pure horizontal regime WWE EEW.

This idea that affiliate production and trade are substitutes when affiliates are horizontal and complements when affiliate production is vertical has popped up frequently in both empirical and theoretical literatures. In addition, due to the fact that data rarely allow the research to distinguish between horizontal and vertical motives, production for local sale is taken as a "smoking gun" for horizontal activity and export sales as a smoking gun for vertical activity. Empirical studies find that production for local sale occurs in large, high-cost, skilled-labor abundant host markets and is encouraged by high trade costs to those markets. Production for export sale is attracted to smaller, low-cost, unskilled-labor-abundant countries with some 
18

evidence that this is discouraged by high trade costs (e.g., Brainard 1997; Carr, Markusen and Maskus 2002; Markusen and Maskus 2001, 2002; Markusen 2002). These associations are closely consistent with the theory developed here and the results shown in Figures 3-5. Horizontal production substitutes for trade in $\mathrm{X}$ and vertical production complements it. Production for local sale occurs when the parent and host are similar, and production for export occurs when the host is small and low cost relative to the parent. 


\section{4. $\quad$ An Asymmetric Case: $\mathrm{W}$ and $\mathrm{S}$ form a Free-Trade Area}

Statistics in Table 1 and the associated discussion above suggest that the export-platform phenomenon may be associate with and encouraged by free-trade areas form by a large (high demand), high-cost partner and a smaller, low-cost developing country. We turn to this case in this section. Suppose that $\mathrm{W}$ and $\mathrm{S}$ form a free-trade area, so all costs between them go to zero. $\mathrm{W}$ will now want to put its single plant in $\mathrm{S}$, and export back to $\mathrm{W}$ and well as serving $\mathrm{E}$ from its plant in S. The situation for the firm in E is more complicated, and that becomes the focus of this section.

Assume that $\mathrm{E}$ has to pay to ship components to $\mathrm{S}$ and pay to ship $\mathrm{X}$ back to $\mathrm{E}$, but that having paid its costs on components it can ship final output costlessly from $\mathrm{S}$ to $\mathrm{W}$. E faces a tradeoff in deciding whether or not to shift its plant to $\mathrm{S}$, or have plants in both $\mathrm{E}$ and $\mathrm{S}$. On the one hand, cost of serving $\mathrm{W}$ will now go down thus encouraging a plant in $\mathrm{S}$. On the other hand, costs of serving its own market go up if S's cost advantage does not outweigh the cost of shipping components to $\mathrm{S}$ and shipping $\mathrm{X}$ back to E. Alternatively, E builds a second plant in $\mathrm{S}$, incurring $\mathrm{G}$ but gaining no savings in its domestic market. In addition to these direct cost effects, there is going to be a strategic or profit-shifting effect in the duopoly competition due to the fact the $\mathrm{E}$ is the high-cost firm.

Assume first that E maintains its single plant in E, so that the regime is (WS, EE). Equilibrium quantities are now:

$$
X_{s w}^{w}=\frac{\alpha-\left(2 c_{s}-c_{n}\right)+\tau_{n}}{3 \beta} \quad X_{s e}^{w}=\frac{\alpha-\left(2 c_{s}-c_{n}\right)-2 \tau_{n}}{3 \beta}
$$




$$
X_{e e}^{e}=\frac{\alpha-\left(2 c_{n}-c_{s}\right)+\tau_{n}}{3 \beta} \quad X_{e w}^{e}=\frac{\alpha-\left(2 c_{n}-c_{s}\right)-2 \tau_{n}}{3 \beta}
$$

Comparing these to the national-firm duopoly in (5) and (6), we see that the $\mathrm{W}$ firm gains sales in both markets, and $\mathrm{E}$ loses sales in both markets since $\mathrm{c}_{\mathrm{s}}<\mathrm{c}_{\mathrm{n}}$. Because profits are quadratic in outputs, there is a shift of profits from firm E to firm W.

Suppose that instead, firm E also shifts its plant to S (regime WS, ES), incurring trade costs on components and costs to shift X back home. Outputs are now:

$$
\begin{array}{ll}
X_{s w}^{w}=\frac{\alpha-c_{s}+\sigma_{n s}}{3 \beta} & X_{s e}^{w}=\frac{\alpha-c_{s}-\tau_{s n}+\sigma_{s n}}{3 \beta} \\
X_{s e}^{e}=\frac{\alpha-c_{s}-\tau_{s n}-2 \sigma_{s n}}{3 \beta} & X_{s w}^{e}=\frac{\alpha-c_{s}-2 \sigma_{s n}}{3 \beta}
\end{array}
$$

Consider the first equations of (27) and (28) which are firm E's profits on its home sales. Comparing these two, we get:

$$
X_{e e}^{e}>X_{s e}^{e} \quad \text { iff } \quad c_{s}+\tau+\sigma>c_{n}
$$

If the second inequality holds, then from the point of view of its home profits, firm $\mathrm{E}$ is better keeping its plant at home. For its sales to W, the second equations of (27) and (29) give us:

$$
X_{s w}^{e}>X_{e w}^{e} \quad \text { iff } \quad c_{s}<c_{n}
$$

which we have assumed to hold.

It should be clear that parameters can be chosen so that both regimes can arise as 
equilibria. If the cost advantage of $\mathrm{S}$ is large so that the inequality on the right-hand side of (30) collapses to an equality, then the regime is (WS, ES): firm E gains sales in W by shifting its plant without losing sales in E. Let $\pi_{\mathrm{i}}^{\mathrm{e}}$ denote the profits of firm $\mathrm{E}$ when it has a plant in region $\mathrm{i}$ (firm $\mathrm{W}$ has its plant in S) and let $\tau$ denote the common value of all $\tau$ and $\sigma$ parameters, except on links where they are zero (WS). Then as the inequality on the right-hand side of (30) collapses to an equality, we have:

(32) $c_{s}+\tau+\sigma \rightarrow c_{n} \quad \pi_{e}^{e}-\pi_{s}^{e}=\left(\alpha-c_{s}-6 \tau\right)^{2} / 9 \beta-\left(\alpha-c_{s}-2 \tau\right)^{2} / 9 \beta<0$

If the cost advantage of $S$ is small so that the inequality on the right-hand side of (31) collapses toward an equality, then E should keep its plant in E and the regime is (WS, EE): its home profits are higher with the plant at home without losing much profit on export sales to $\mathrm{W}$ from $\mathrm{E}$ rather than from $\mathrm{S}$. As the inequality on the right-hand side of (30) collapses to an equality, we have:

$$
c_{s} \rightarrow c_{n} \quad \pi_{e}^{e}-\pi_{s}^{e}=\left(\alpha-c_{s}+\tau\right)^{2} / 9 \beta-\left(\alpha-c_{s}-3 \tau\right)^{2} / 9 \beta>0
$$

The final possibility is that firm $\mathrm{E}$ will maintain plants in both $\mathrm{E}$ and $\mathrm{S}$, so that the regime is (WS, EES). In this case, equilibrium quantities are:

$$
\begin{array}{ll}
X_{s w}^{w}=\frac{\alpha-c_{s}+\sigma_{n s}}{3 \beta} & X_{s e}^{w}=\frac{\alpha-\left(2 c_{s}-c_{n}\right)-2 \tau_{s n}}{3 \beta} \\
X_{e e}^{e}=\frac{\alpha-2\left(c_{n}-c_{s}\right)+\tau_{s n}}{3 \beta} & X_{s w}^{e}=\frac{\alpha-c_{s}-2 \sigma_{s n}}{3 \beta}
\end{array}
$$

This outcome will arise (if at all) for values of $c_{s}$ and $c_{n}$ where the both the (strict) inequalities in 
(27) and (28) hold and G, the cost of a second plant, is not too big. Inequality (31) implies that firm $\mathrm{E}$ would like to serve $\mathrm{W}$ from a plant in $\mathrm{S}$. Inequality (30) implies that firm $\mathrm{E}$ would like to serve $\mathrm{E}$ from a local plant. Thus as $\mathrm{G}$ approaches zero, the regime must be (WS, EES) under the assumption that both of these inequalities hold (note firm $\mathrm{W}$ will not want a second plant even as G goes to zero). We expect to find (WS, EES), if at all, for values of $c_{s}$, for example, between those that generate (WS, EE) and (WS, ES). The regime (WS, EES) is an interesting case for us, since E's investment in S is a case of pure export-platform FDI. All output of the plant in S is exported to $\mathrm{W}$.

Suppose that without the free-trade area, the equilibrium would be the symmetric national-firm outcome WW EE in (7) and (8). A comparison of (7)-(8) to (27) and (35) leads to the conclusion that firm E must be worse off by the W-S free-trade area if E keeps a plant at home. However, comparing (7)-(8) to (29) shows that it is possible that firm E is also better off when the cost advantage of $\mathrm{S}$ is sufficiently large that it maintain just a single plant in $\mathrm{S}$ (WS, ES). Take the case discussed above, where the cost advantage of $\mathrm{S}$ is sufficiently large that inequality (30) collapses toward an equality (firm E will abandon its plant before this becomes an equality in order to save G). In that case, the regime shift from (WS, EE) or (WS, EES) to (WS, ES) has no effect in E's profits at the regime shift, and must increase E's profits as $\mathrm{c}_{\mathrm{s}}$ continues to fall thereafter. Both firms' profits must now increase as $\mathrm{c}_{\mathrm{s}}$ falls more. However, note from (28) and (29) that firm W is the larger gainer, having bigger sales in both markets than firm E.

Figures 6, 7, and 8 present some simulation results, where some underlying parameters differ among the figures in order that we get three or four regime shifts as we change the parameter along the horizontal axis. Figure 6 lowers the production cost in $\mathrm{S}, \mathrm{c}_{\mathrm{s}}$, beginning at a 
value of 4 which is equal to $c_{n}$, so that initially the free-trade area as no advantage to firm $\mathrm{W}$. As costs in the south fall moving to the right, firm $\mathrm{W}$ obviously profits and firm $\mathrm{E}$, while not directly affect suffers losses due its disadvantage in the duopoly game. The first regime shift is that firm E builds a second plant in S, keeping its plant at home, so this is our case of pure export-platform production for firm $\mathrm{E}$. This adversely affects firm $\mathrm{W}$ since firm $\mathrm{E}$ is now more competitive in $\mathrm{W}$, while there are no changes in market E, so firm W's profits have a discrete negative jump at this regime shift. The final regime shift is to WS ES, firm E abandoning its home plant. This raises the (marginal) cost to firm E of serving its home market, creating a beneficial competitive effect for firm $\mathrm{W}$ whose profits jump up at this shift. Further reductions in $\mathrm{c}_{\mathrm{s}}$ improve the profits of both firms.

Figure 7 lowers the costs of trading components and $\mathrm{X}$ on $\mathrm{W}-\mathrm{E}$ and $\mathrm{E}-\mathrm{S}$ links. There is world free trade on the right-hand end of the diagram so of course due to symmetry the profits of the two firms are equal. Profits of firm E shift smoothly, and the discrete jumps in the profits of firm $\mathrm{W}$ at the regime shifts are due to the same competitive effects noted earlier. It is interesting to note that in the right-hand region WS ES, further falls in E-S trade costs harm firm W even though firm $\mathrm{W}$ has the costs of shipping $\mathrm{X}$ to $\mathrm{E}$ reduced. The reason is again a competitive effect that is larger than this cost-reduction effect: firm E can now ship components more cheaply to $\mathrm{S}$ which makes it more competitive in both markets.

Figure 8 shows a gradual reduction in trade costs on W-S links with the full free-trade area on the right-hand edge. In the initial symmetric situation, the national firm duopoly WW EE is the equilibrium (due to the choice of values for $\mathrm{c}_{\mathrm{s}}$ and $\mathrm{G}$ ). The first move is that firm $\mathrm{W}$ closes its home plant and opens a plant in $\mathrm{S}$ to serve both markets. Firm $\mathrm{W}$ has an incentive to move 
first because, while both firms can ship $\mathrm{X}$ from $\mathrm{S}$ to $\mathrm{W}$ more cheaply, only firm $\mathrm{W}$ can get its components into S more cheaply. After this point, there is obviously not going to be a further shift by firm $\mathrm{W}$, so the next two regime shifts are due to changes by firm $\mathrm{E}$ and these are the same one occurring in the previous two diagrams: first $\mathrm{E}$ builds a pure export-platform plant in $\mathrm{S}$, and then at a very low S-W trade cost firm E closes its home plant. This last shift is another indirect competitive effect. Falling trade costs on the W-S link mean that firm W gains an increased market share in E due to its ability to get its components to its S plant more cheaply. Eventually, firm E finds its (Cournot) output reduced to the point where it should bear a trade costs of serving its own market from $\mathrm{S}$ rather than the fixed cost $\mathrm{G}$ of having plants in both locations. The discrete jumps in the profits of firm $\mathrm{W}$ are once again for the competitive reasons already discussed.

There are several interesting policy points to consider arising from these indirect competitive effects. First, a firm in a high-wage country is going to be hurt if its rival negotiates a free-trade deal with a low-wage partner. If your rival is going to get a low-wage partner, you better do so too. Second, we saw in all three figures (6-8) that firm W experienced a discrete drop in profits when its eastern rival put a plant into $\mathrm{S}$. This points to an incentive for firms inside the free-trade area to keep outside firms outside. There are a number of cases where we think that inside firms apparently try to maniplulate rules so raise the costs of outside firms entering. One is minimum domestic-content requires or rules of origin, that inside firms want to maintain at a very high level in order to raise their outside rival's cost of entry (Lopez-de-Silanes, Markusen, Rutherford, 1996). In our model here, if the components firm E imports into S give a total domestic content for its $\mathrm{X}$ that is below the requirement to be consisdered made in the free- 
trade area, then firm $\mathrm{E}$ would have to pay to ship its product from $\mathrm{S}$ to $\mathrm{W}$, raising its costs or deterring it from entering al together.

\section{5. $\quad$ Summary}

Export-platform direct investment is usually taken to refer to a situation where the output of a foreign subsidiary is largely sold in third markets, not in the host country or exported back to the parent country. Our approach adopts a three-country model, with two identical large, highcost countries and a small, low-cost country. Pure export-platform investments occur when a firm in one or both of the large high-cost countries builds a plant in the low-cost country solely to supply the other large, high-cost country while retaining a plant at home to serve the local market.

We consider two cases. In the first, trade costs for components are the same on all trade links as are the trade costs for assembled $\mathrm{X}$. The pure export-platform case is preferred on a cost basis if the cost disadvantage of the north is (a) large relative to the cost of shipping final output (so that a horizontal strategy is not preferred) and (b) large relative to the cost of shipping components and the per-unit fixed costs of a second plant (so that a national-firm strategy is not preferred), but (c) not large relative to the cost of shipping components to S, and shipping final output back to the home and incurring the added per-unit fixed costs of the second plant (so that a single plant in $\mathrm{S}$ is not preferred). These findings are generally valid when we solve for the sub-game perfect Nash equilibrium of the game.

Results of this case also complement other results in the theoretical and empirical literatures. Horizontal affiliate production substitutes for trade while vertical or export-platform 
production complements trade. Horizontal affiliates arise between large, similar countries, while vertical and export platform production arise between a parent in a high-cost country and a lowcost developing country.

Our second case involves export-platform FDI arising in a situation where one (of several) high-demand, high-cost countries forms a free-trade area with a low-cost, low-demand country, and final assembly is suited to the latter's factor endowment and costs. If there are two high-wage countries, then firms in both those countries may have an incentive to set up a plant in the low-wage country. The firm in the country partnered with the low-wage country has an incentive to locate a single assembly plant in that country to serve its own market (traditional vertical investment) and serve the other high-cost country using the plant as a export platform. An example would be a US firm serving Europe from a plant in Mexico.

The firm in the outside country may also have an incentive to locate a plant in the lowcost country in order to serve its rival by exports from that plant. An example would be a European firm serving the US from a plant in Mexico. We show that there exists a range of production and trade costs for which the outside high-cost country makes a pure export-platform investment, serving its home market with a local plant and the foreign high-cost market from a plant in the latter's low-wage partner.

The partner country's firm shifts its plant at a lower cost advantage for $S$ than does the outside firm, since the partner firm can ship components to $\mathrm{S}$ cost free while the outside firm must pay a cost to ship its components to $\mathrm{S}$. And for the parameter range we examine, the partner firm never makes a pure-export platform investment, always opting to serve both its home market and the other high-cost country from the plant in the low cost country, but we 
cannot rule out such a solution. As indicated in the previous paragraph, there are a wide range of values for which the outside firm makes a pure export-platform investment.

Results in this paper and other well known results from the strategic trade-policy literature, imply that the two firms are better off with some symmetric protection than in bilateral free trade. Thus the shift to export-platform production in the symmetric case initially lowers the profits of both firms in the usual prisoners' dilemma way. In the case of the asymmetric freetrade area, the firm that does find the low-wage partner benefits and the other firm loses, again due to the usual profit-shifting effect we are familiar with. Results then imply that the outside firm should respond by finding a low-wage partner as well. 


\section{REFERENCES}

Arndt, Sven W. and Henryk Kierzkowski, editors (2000), Fragmentation: New Production Patterns in the World Economy, Oxford: Oxford University Press.

Blonigen, Bruce (2001), "In Search of Substitution between Foreign Production and Exports", Journal of International Economics 53, 81-104.

Braconier, Henrik and Karolina Ekholm (2001), "Foreign Direct Investment in Central and Eastern Europe: Employment Effects in the EU”, CEPR working paper No. 3052.

Braconier, Henrik and Karolina Ekholm (2000), "Swedish Multinationals and Competition from High and Low-Wage Countries", Review of International Economics 8, 448-461..

Brainard, S. Lael (1997), "An Empirical Assessment of the Proximity-Concentration Tradeoff between Multinational Sales and Trade", American Economic Review 87, 520-544.

Carr, David, James R. Markusen and Keith E. Maskus (2001), "Estimating the KnowledgeCapital Model of the Multinational Enterprise", American Economic Review 91, 693708.

Hanson, G. H., Mataloni, R. J., Slaughter, M. J. (2001), "Expansion Strategies of U.S. Multinational Firms", in Dani Rodrik and Susan Collins (eds.), Brookings Trade Forum 2001, 245-294.

Jones, Ronald W. (2000), Globalization and the Theory of Input Trade, Cambridge: MIT Press.

Lopez-de-Silanes, Florencio, James R. Markusen and Thomas Rutherford, "Trade Policy Subtleties with Multinational Firms", European Economic Review 40 (1996), 1605-1627.

Markusen, James R (2002), Multinational Firms and the Theory of International Trade, Cambridge: MIT Press.

Markusen, James R. and Keith E. Maskus (2001), "Multinational Firms: Reconciling Theory and Evidence", in Magnus Blomstrom and Linda Goldberg (editors), Topics in Empirical International Economics: A Festschrift in Honor of Robert E. Lipsey, Chicago: University of Chicago Press, forthcoming.

Markusen, James R. and Keith E. Maskus (2002), "Discriminating among Alternative Theories of the Multinational Enterprise", Review of International Economics 10, 694-707.

Motta, Massimo and George Norman (1996), "Does Economic Integration Cause Foreign Direct Investment”, International Economic Review 37, 757-783. 
Appendix - Algebra of Profits and Nash Equilibria

The simple duopoly model with linear demand and constant marginal costs is probably quite well known. Nevertheless, we derive some of the algebra in this section. $\mathrm{Y}$ is an "outside good", produced with constant returns from a single factor labor, where one unit of labor produces one unit of Y. Labor and Y are numeraire, and the subscript 'c' a good denotes the quantity consumed from all sources. First, the linear demand functions can be derived from the usual quasi-linear utility function, maximized subject to a budget constraint where income is derived from labor and profits.

$$
U_{i}=\alpha X_{c i}-(\beta / 2) X_{c i}^{2}+Y_{c i} \quad L+\pi_{i}=Y_{c i}+p_{i} X_{c i}
$$

Maximization of $U$ subject to the budget constraint yields the demand functions:

$$
\text { (A2) } p_{i}=\alpha-\beta X_{c i} \quad p_{i} X_{i}=\alpha X_{i}-\beta X_{c i}^{2}
$$

The quadratic profit expressions in (11)-(15) are also reasonable well know. Here we just derive the results for the case where each northern firm serves the other northern market by exports. Ignoring fixed costs, the profit equations:

$$
\begin{array}{ll}
\pi_{i}=p_{i} X_{i i}-c X_{i i}+p_{j} X_{i j}-(c+\tau) X_{i j} & p_{i}=\alpha-\beta\left(X_{i i}+X_{j i}\right) \\
\pi_{j}=p_{j} X_{j j}-c X_{j j}+p_{i} X_{j i}-(c+\tau) X_{j i} & p_{j}=\alpha-\beta\left(X_{j j}+X_{i j}\right)
\end{array}
$$

Due to the symmetry assumptions, we can just consider the market in region $\mathrm{i}$.

$$
\begin{aligned}
& \frac{d \pi_{i}}{d X_{i i}}=\alpha-2 \beta X_{i i}-\beta X_{j i}-c=0 \\
& \frac{d \pi_{j}}{d X_{j i}}=\alpha-2 \beta X_{j i}-\beta X_{i i}-c-t=0
\end{aligned}
$$


Substitute the first equation of (A4) into the second.

(A5) $\quad \alpha-2 \beta X_{j i}-\frac{\alpha}{2}+\frac{\beta}{2} X_{j i}+\frac{c}{2}-c-t=0$

(A6) $\frac{\alpha}{2}-\frac{3}{2} \beta X_{j i}-\frac{c}{2}-t=\alpha-3 \beta X_{j i}-c-2 t=0$

(A7) $\quad X_{j i}=\left[\frac{\alpha-c-2 t}{3 \beta}\right]$

Now solve for $\mathrm{X}_{\mathrm{ii}}$ using the first equation of (A4).

(A8) $\alpha-2 \beta X_{i i}-\frac{\alpha-c-2 t}{3}-c=0$

(A9) $\frac{2}{3} \alpha-2 \beta X_{i i}-\frac{2}{3} c+\frac{2}{3} t=\frac{\alpha}{3}-\beta X_{i i}-\frac{c}{3}+\frac{t}{3}=0$

(A10) $X_{i i}=\left[\frac{\alpha-c+t}{3 \beta}\right]$

Now substitute (A7, A10) into the profit equation for firm i to get profits on domestic sales before (net of) fixed costs.

(A11) $\pi_{i i}=\left[\alpha-\beta\left[\frac{2(\alpha-c-t / 2)}{3 \beta}\right]-c\right]\left[\frac{\alpha-c+t}{3 \beta}\right]$

(A12) $\pi_{i i}=\left[\alpha-\frac{2}{3} \alpha+\frac{2}{3} c+\frac{t}{3}-c\right]\left[\frac{\alpha-c+t}{3 \beta}\right]=\left[\frac{\alpha-c+t}{3}\right]\left[\frac{\alpha-c+t}{3 \beta}\right]$

(A13) $\pi_{i i}=\beta\left[\frac{\alpha-c+t}{3 \beta}\right]^{2}=\beta X_{i i}^{2}$

Follow the same procedure for firm $\mathrm{j}$, substituting (A10) into its profit equation.

$$
\pi_{j i}=\left[\alpha-\beta\left[\frac{2(\alpha-c-t / 2)}{3 \beta}\right]-c-t\right]\left[\frac{\alpha-c-2 t}{3 \beta}\right]
$$


(A15)

$$
\pi_{j i}=\left[\alpha-\frac{2}{3} \alpha+\frac{2}{3} c+\frac{t}{3}-c-t\right]\left[\frac{\alpha-c-2 t}{3 \beta}\right]=\left[\frac{\alpha-c-2 t}{3}\right]\left[\frac{\alpha-c-2 t}{3 \beta}\right]
$$

(A16) $\pi_{j i}=\beta\left[\frac{\alpha-c-2 t}{3 \beta}\right]^{2}=\beta X_{j i}^{2}$

The result that profits in a given market are quadratic in output is true for almost all versions of this model, including when marginal costs differ between regions, etc. The formula remains the same, but of course the value of that formula changes according to the assumptions.

A second task of this appendix is to illustrate some of the analytical conditions for a Nash equilibrium. The difficulty is that the firm's outputs differ in the different regimes and profits are quadratic in these differing outputs. This makes it difficult to get clear intuition as to how parameter values determine the Nash equilibrium regime. Here we will just present a couple of sample conditions, which are used in (23)-(26) in the body of the paper. All results refer to the symmetric case.

(A) Firm W cannot profitably deviate from WWS EES to WWE EES

For the pure export-platform case to be an equilibrium, it must not be profitable for a firm to choose to locate its second plant in the other northern country instead of in the South. Suppose that we are in the former configuration, and $\mathrm{W}$ considers shifting its second plant from S to E. This is very straightforward, since it does not involve changes in fixed costs, and no change by either firm in market W. Thus from (14)-(15), all that we need to check is whether or not W's equilibrium supply to E is larger under WWS or WWE. The condition for a deviation from WWS to WWE to be unprofitable is:

(A17) $X_{e e}^{w}=\left[\alpha-2\left(c_{n}+\sigma\right)+c_{n}\right] /(3 \beta)<X_{s e}^{w}=\left[\alpha-2\left(c_{s}+\sigma+\tau\right)+c_{n}\right] /(3 \beta)$ 
This simplies to

(A18) $c_{n}-c_{s}=\Delta c>\tau$ (firm W deviation from WWS EES to WWE EES unprofitable)

which is the same as the second inequality in (20).

Conditions in which the number of plants change along with output are much more complicated due to the fact that variable profits are quadratic in outputs. For the pure exportplatform case to be an equilibrium, it cannot be profitable for firm $\mathrm{W}$ to deviate from WWS to WS, serving both markets from $S$ given that firm E chooses EES.

(B) Firm W cannot profitably deviate from WWS EES to WS EES

There is no change in either firm's supply to market E, so we just need to compare firm W's supplies to its own market taking into account that WS involves one less G. The condition for this deviation to be unprofitable is:

$$
\left[\alpha-2\left(c_{s}+\sigma+\tau\right)+\left(c_{s}+\sigma+\tau\right)\right]^{2}<\left[\alpha-2 c_{n}+\left(c_{s}+\sigma+\tau\right)\right]^{2}-9 \beta G
$$

$$
\left[\alpha-c_{s}-\sigma-\tau\right]^{2}<\left[\alpha-2 c_{n}+c_{s}+\sigma+\tau\right]^{2}-9 \beta G
$$

Add and subtract $\mathrm{c}_{\mathrm{n}}$ from the left hand term in brackets:

(A21) $\left[\alpha-c_{n}+\left(c_{n}-c_{s}-\sigma-\tau\right)\right]^{2}<\left[\alpha-c_{n}-\left(c_{n}-c_{s}-\sigma-\tau\right)\right]^{2}-9 \beta G$

Let $\left(\alpha-c_{n}\right) \equiv \gamma$ and $\left(c_{n}-c_{s}-\sigma-\tau\right) \equiv \delta$, then (A22) can be written as:

(A22) $(\gamma+\delta)^{2}<(\gamma-\delta)^{2}-9 \beta G$ or $2 \gamma \delta<-2 \gamma \delta-9 \beta G$

Collecting terms and dividing through by $4 \gamma$, this becomes

(A23) $c_{n}-c_{s}-\sigma-\tau=\Delta c-\sigma-\tau<-\frac{9 \beta}{4 \gamma} G \quad$ or 
(A24) $\Delta c<\sigma+\tau-\frac{9 \beta}{4 \gamma} G=\sigma+\tau-\frac{3}{4}\left[\frac{3 \beta}{\alpha-c_{n}}\right] G$

The term in square brackets looks like an X quantity. Referring back to (7)-(8), for example,

$$
\frac{X_{w w}^{w}+X_{e e}^{w}}{2}=\frac{\alpha-c_{n}-\sigma / 2}{3 \beta}<\frac{\alpha-c_{n}}{3 \beta} \quad \frac{2}{X_{w w}^{w}+X_{e e}^{w}} \equiv \frac{1}{X_{h}^{w}}>\frac{3 \beta}{\alpha-c_{n}}
$$

where $X_{h}^{w}$ is defined as the average output per plant of a firm in the horizontal equilibrium (7)-

(8). The right-hand bracketed term in (A24) times G is much like plant fixed-cost per unit of output, which is how we defined $\mathrm{g}$ in (17)-(21). Using (A25), a sufficient condition for (A24) to hold is then that

(A26) $\Delta c<\sigma+\tau-\frac{3}{4}\left[\frac{G}{X_{h}^{w}}\right]$

a condition similar to the first inequality in (20) (if g is "properly" defined).

(C) Firm W cannot profitably deviate from WWS EES to WW EES

The procedure here is similar the deviation just considered. There is no change in either firm's supply to market W, so we just need to compare firm W's supplies to its E's market taking into account that WW involves one less G. The condition for this deviation to be unprofitable is:

$$
\left[\alpha-2\left(c_{n}+\tau\right)+c_{n}\right]^{2}<\left[\alpha-2\left(c_{s}+\sigma+\tau\right)+c_{n}\right]^{2}-9 \beta G
$$

(A28) $\left[\alpha-c_{n}-2 \tau\right]^{2}<\left[\alpha-2 c_{s}+c_{n}-2 \sigma-2 \tau\right]^{2}-9 \beta G$

Add and subtract $\mathrm{c}_{\mathrm{n}}$ from the right-hand term in brackets:

(A29) $\left[\alpha-c_{n}-2 \tau\right]^{2}<\left[\left(\alpha-c_{n}-2 \tau\right)+2\left(c_{n}-c_{s}-\sigma\right)\right]^{2}-9 \beta G$ 
Following similar procedures, this can be reduced to:

$$
\Delta c>\sigma+\frac{3}{4}\left[\frac{3 \beta}{\alpha-c_{n}-2 \tau}\right] G-\frac{\left(c_{n}-c_{s}-\sigma\right)^{2}}{\alpha-c_{n}-2 \tau}=\sigma+\frac{3}{4}\left[\frac{G}{X_{w e}^{w}}\right]-\frac{\left(c_{n}-c_{s}-\sigma\right)^{2}}{\alpha-c_{n}-2 \tau}
$$

where $X_{w e}^{w}$ is the quantity a firm exports to the other northern market in the national firm duopoly

from (5) and (6). It follows that a sufficient condition for this deviation to be unprofitable is:

(A31) $\Delta c>\sigma+\frac{3}{4}\left[\frac{G}{X_{w e}^{w}}\right] \quad$ similar to the third inequality in (20)

The final task of this appendix is to comment on the possibility of asymmetric equilibrium outcomes in the symmetric case. We never found one numerically (and the simulation program finds all pure-strategy Nash equilibria), but did not provide a proof that no asymmetric outcomes can be equilibria. We believe that this is the case, unless fixed costs become so high that only one firm can exist in equilibrium (see Markusen 2002, chapter 3).

The easiest cases to rule out are asymmetric outcomes in which each firm has a plant in its own market. Consider the 3x3 set out regimes formed by firm W having strategies WW, WWE, and WWS, and firm E having strategies EE, EEW, and EES. In all these cases, deviation from a symmetric regime to an asymmetric regime by one firm affects outputs in only one market, and if this is profitable for the firm, the same deviation must be profitable for the other firm. Suppose for example that we are in WWE EEW and firm W deviates to WWS. This only affects firm W's supply to E, which shifts from production in E to production in S exported to E. If this deviation is profitable for $\mathrm{W}$, then by the symmetry of the model, it must also be profitable for firm E to deviate from EEW to EES by exactly the same argument, since this deviation only 
affects supplies in $\mathrm{W}$ and thus the incentive for the deviation is unaffected by firm W's deviation. This same chain of reasoning is valid for all asymmetric outcomes in the $3 \times 3$ set of strategies.

In addition, it allows us to rule the asymmetric strategy WS EES by the same argument: beginning at WWS EES, if W can profitably deviate to WS this affects firm W's supplies only to market $\mathrm{W}$. If this is profitable for firm $\mathrm{W}$, then by exactly the same argument firm $\mathrm{E}$ should eliminate its plant at home serves its home market from a plant in S only.

Consider the symmetric outcome WW EE and firm W deviating to WS, which changes firm W's supplies to both markets. If this is marginally profitable for W, it must be that it gains sales in E that just outweigh losses of sales in W. But this shift in its pattern of supply increases the incentive of firm $\mathrm{E}$ to make a similar deviation from EE to ES, redirecting the latter's supply toward W.

We have now ruled out all asymmetric equilibrium except WS EEW (and of could WWE ES), which is more tricky to eliminate since supplies to both markets change. Suppose instead that the initial configuration is WWE EEW, and firm W considers deviating to WS. It appears that the correct argument here is that if this deviation is marginally profitable, then it is even better for W to deviate to WWS (i.e., profit indifference for firm W between WWE EEW and WS EEW for firm W implies positive profits in WWS EEW). But then if this is profitable, then by an earlier argument firm E should also deviate to EES. While these arguments are clearly somewhat informal, we feel that they do rule out asymmetric equilibria in this (symmetric) model and again, none were found in countless simulations. 
Table 1: Distribution of sales by US affiliates between local sales, exports to the US, exports to third countries

Sales of foreign affiliates of US multinationals: shares in total, 1993-94

$\begin{array}{lll}\text { local } & \begin{array}{l}\text { export sales } \\ \text { sales }\end{array} & \begin{array}{l}\text { export sales to } \\ \text { to the US }\end{array}\end{array}$

$\begin{array}{llll}\text { All countries } & 0.60 & 0.14 & 0.26 \\ & & & \\ \text { Ireland } & 0.15 & 0.09 & 0.76 \\ \text { Belgium } & 0.34 & 0.05 & 0.60 \\ \text { Holland } & 0.38 & 0.04 & 0.59 \\ & & & \\ \text { Singapore } & 0.17 & 0.50 & 0.33 \\ \text { Malaysia } & 0.28 & 0.41 & 0.31 \\ \text { Hong Kong (93 only) } & 0.45 & 0.21 & 0.34 \\ & & & \\ \text { Canada } & 0.54 & 0.43 & 0.03 \\ \text { Mexico } & 0.66 & 0.31 & 0.03\end{array}$


Figure 1: Regimes as a function of cost of trading components, production cost in $\mathrm{S}$
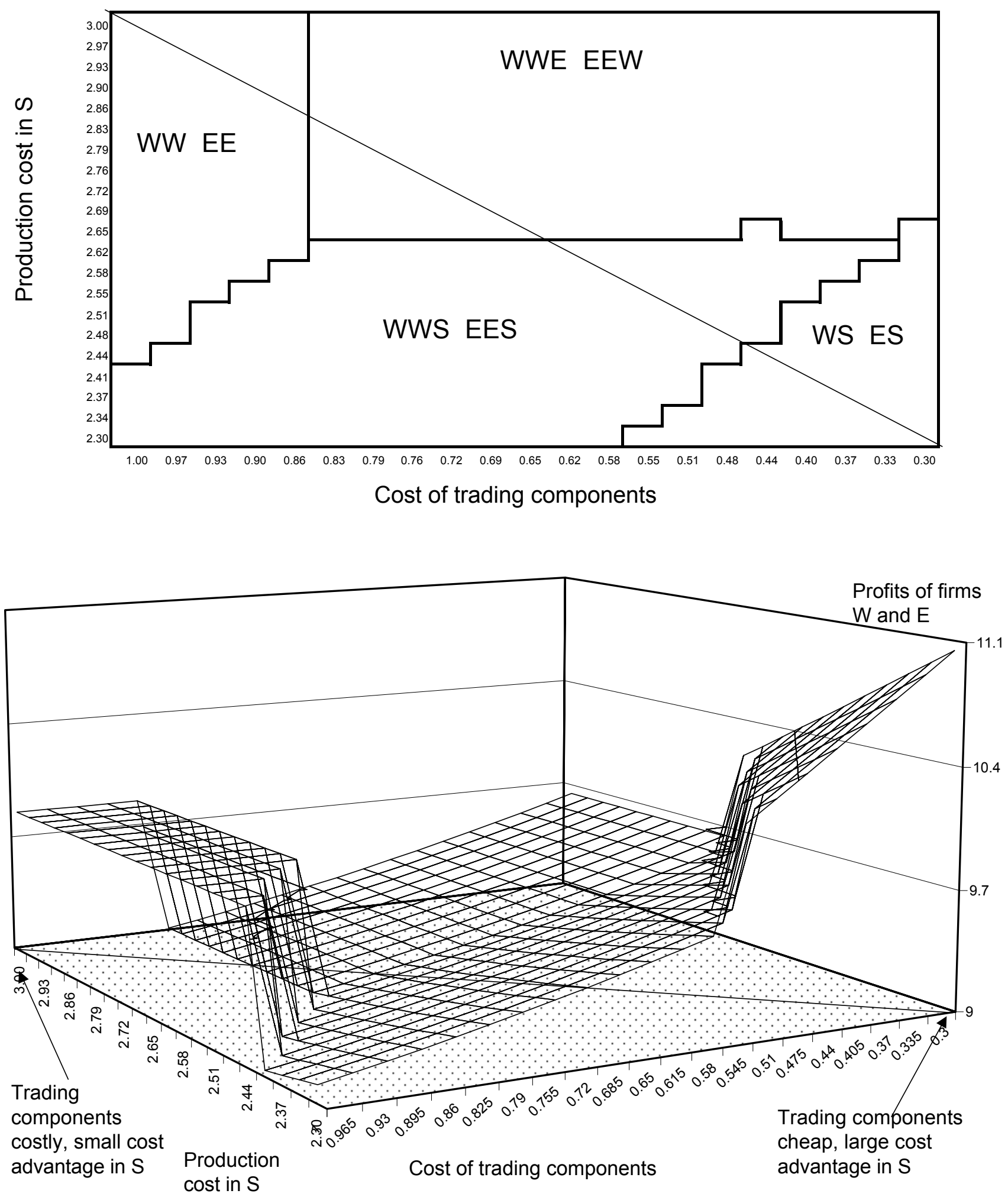
Figure 2: Symmetric model, lower cost of trading components, and production cost in South

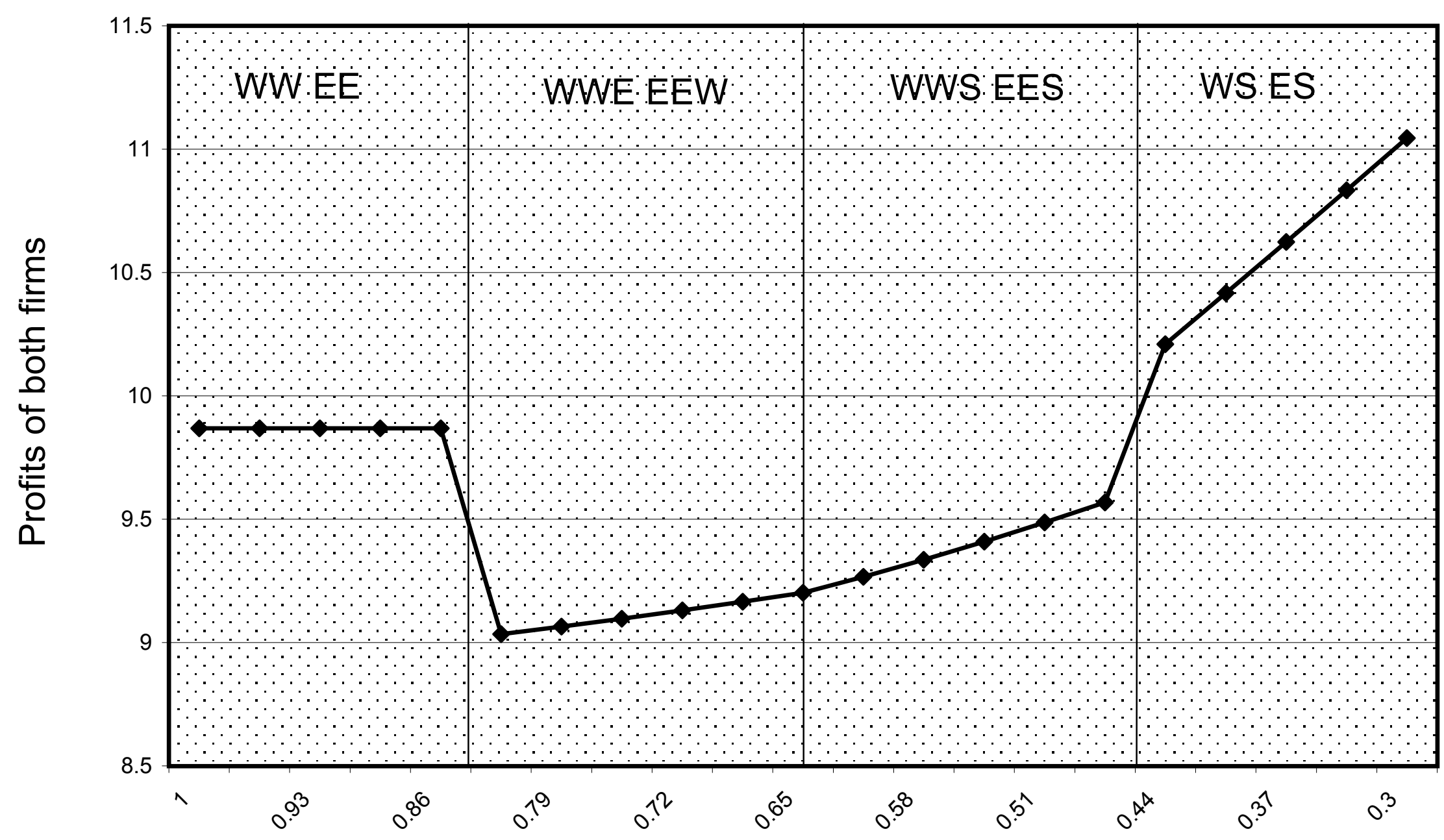

Cost of component trade $\sigma$ lowered in $3.5 \%$ steps, $\mathrm{c}_{\mathrm{s}}$ lowered in $0.833 \%$ 
Figure 3: Volume of affiliate production

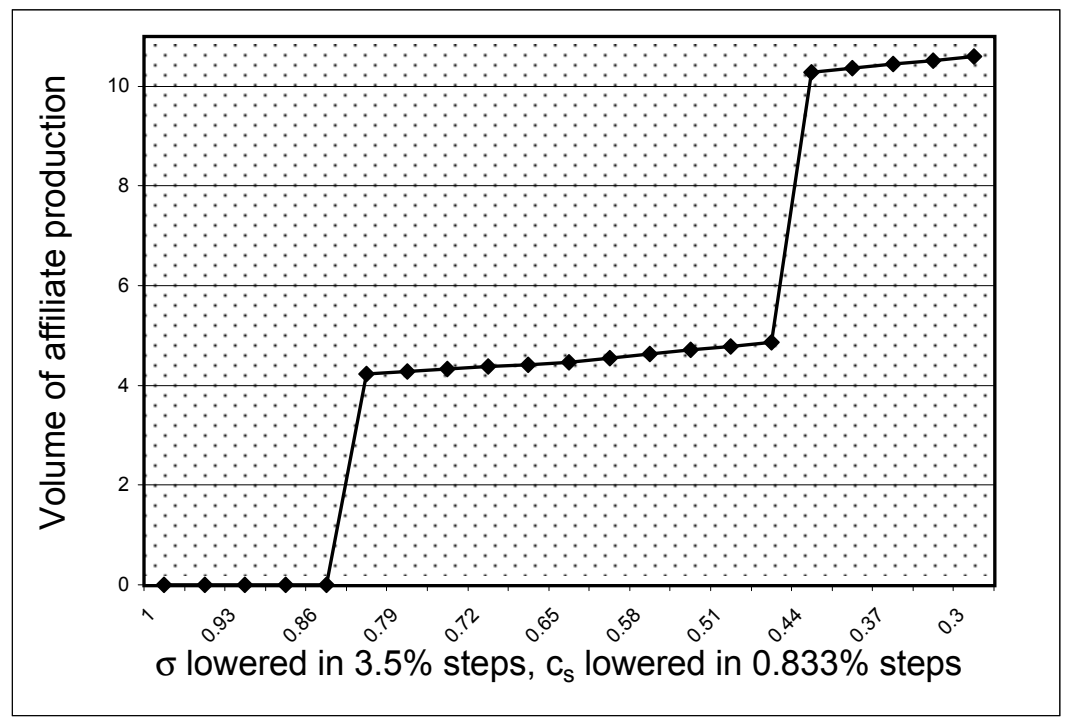

Figure 4: Volume of trade in assembled $\mathrm{X}$

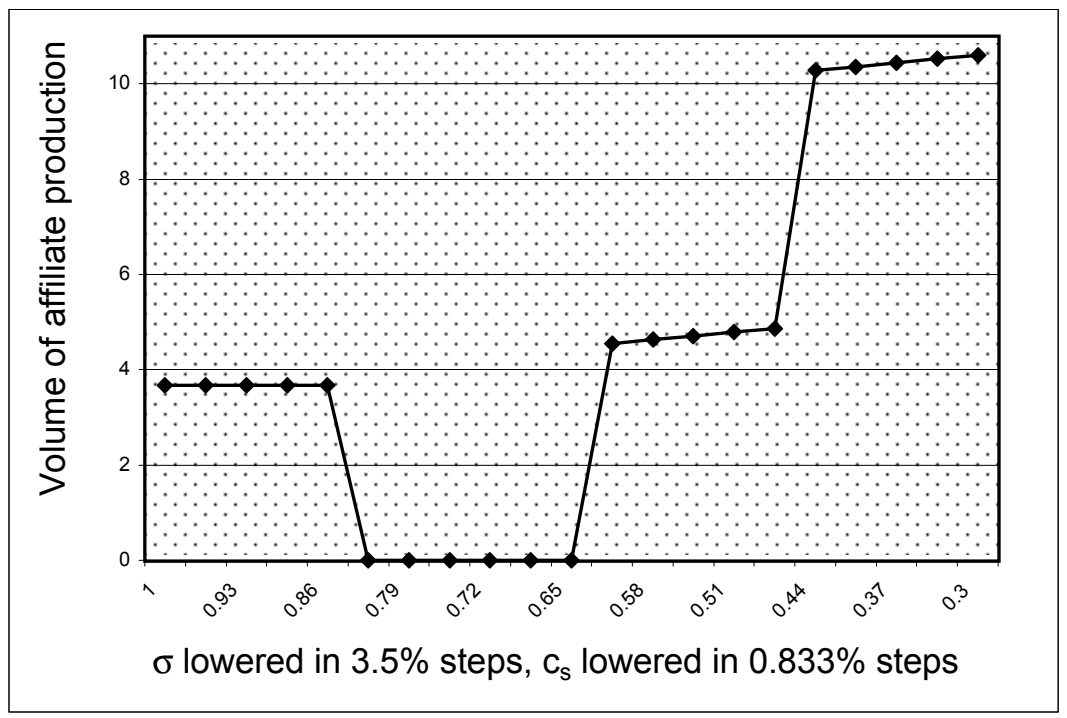

Figure 5: Volume of trade in assembled $\mathrm{X}$ and components

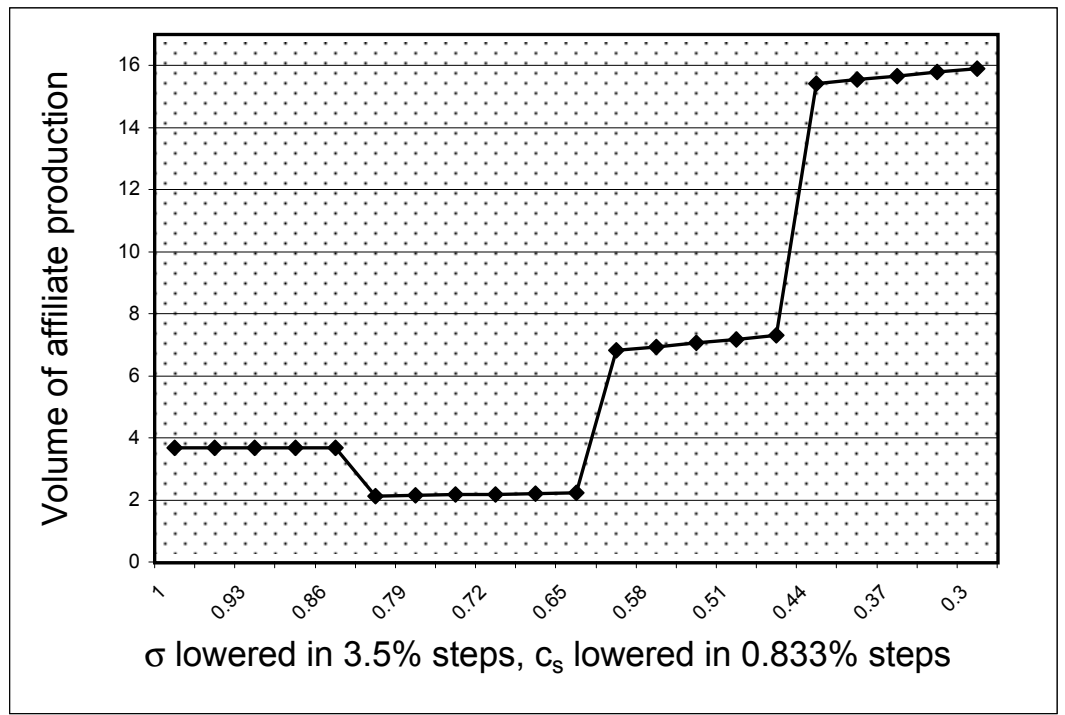


Figure 6: Profits of Firms W and E: West and South in free-trade area $(G=1.9)$

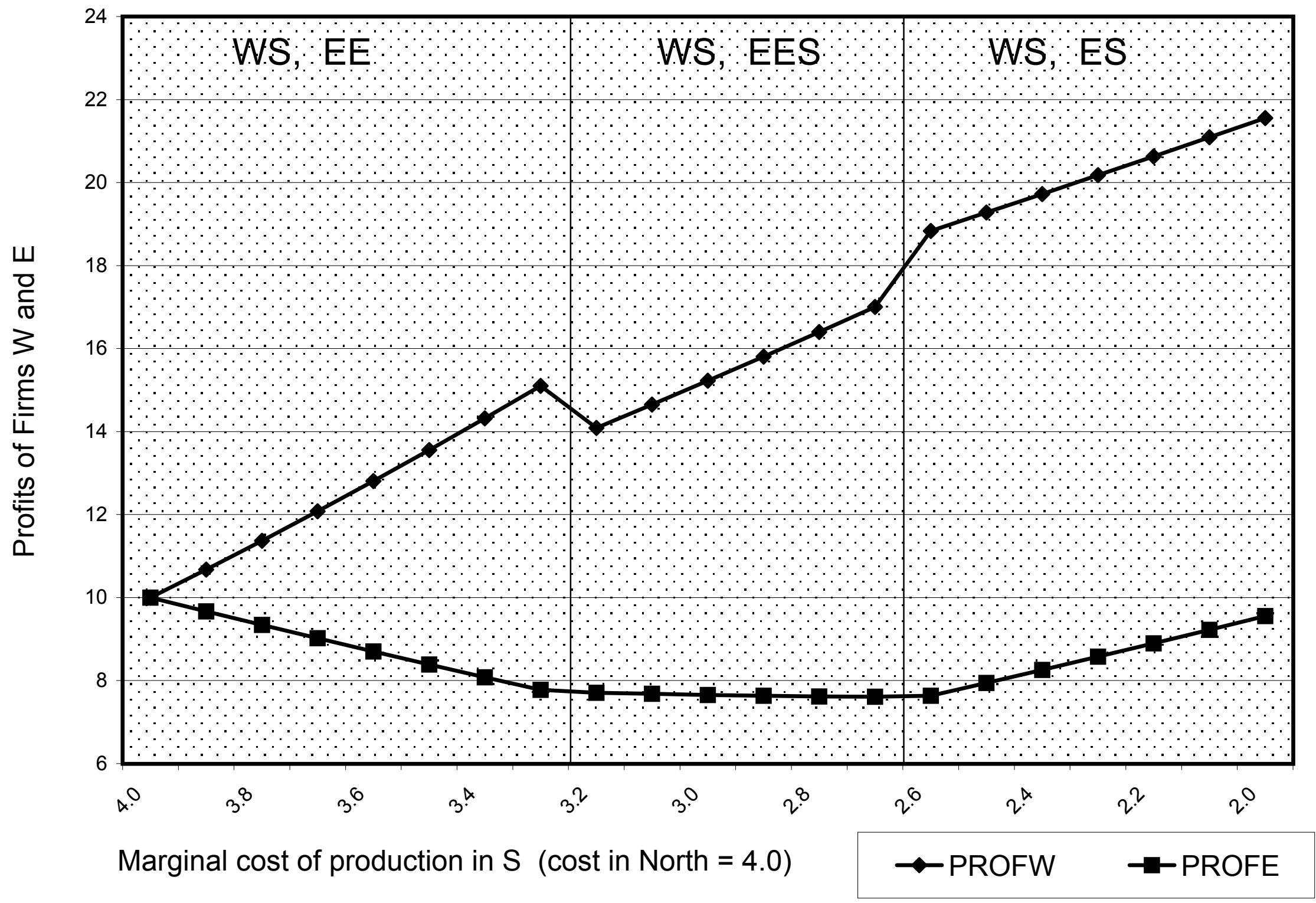


Figure 7: Profits of Firms W and E: West and South in free-trade area $\left(c_{s}=3.5, G=1.4\right)$

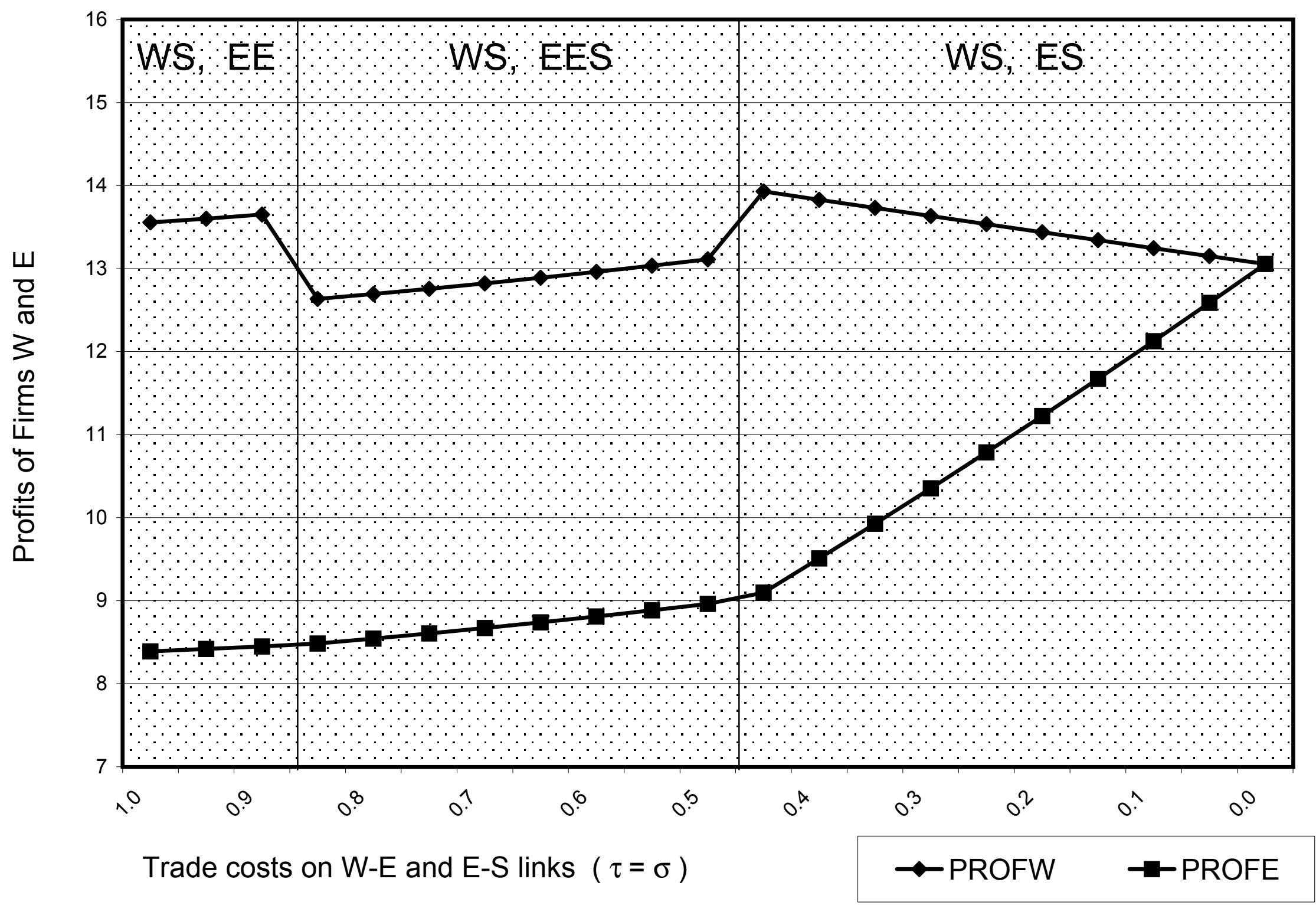


Figure 8: Profits of Firms $\mathrm{W}$ and $\mathrm{E}$ : Reduce trade costs between West and South $\left(c_{s}=2.7, G=2.2\right)$

WS, ES

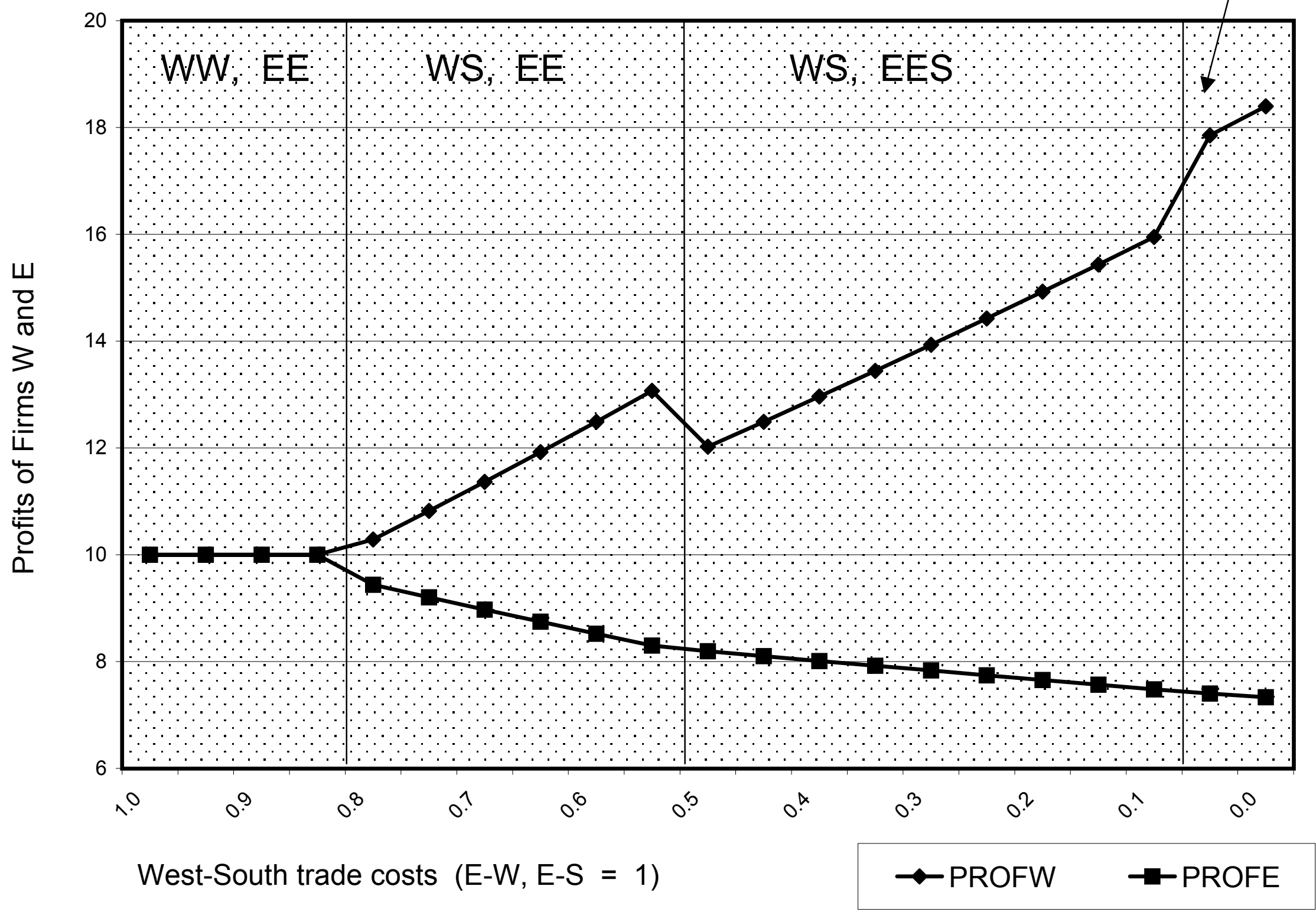

